\title{
COMPARAÇÃO NO RENDIMENTO DE PRÉ-TRATAMENTOS NA HIDRÓLISE DO BAGAÇO DE ABACAXI PARA PRODUÇÃO DE BIOCOMBUSTÍVEIS.
}

\author{
A. A. SEOLATTO ${ }^{1}$, T. P. P.MENDES ${ }^{1}$, F.F. FREITAS ${ }^{1}$, M. B. PEREIRA ${ }^{1}$, E.M.S. NETO ${ }^{1}$, R. B. B. \\ PY. \\ ${ }^{1}$ Universidade Federal de Goiás, Instituto de Química \\ E-mail para contato: araceliseolatto@gmail.com
}

\begin{abstract}
RESUMO - O uso do bagaço como biomassa para a produção de bioetanol apresenta uma série de vantagens: já vem processado das indústrias, está disponível em grandes quantidades, tem custo mínimo, está pronto para uso no local, evitando aumento de custo devido ao transporte. Neste sentido, este trabalho teve por objetivo a análise do desempenho do bagaço do abacaxi, oriundo de indústrias de suco, submetido ao prétratamento com hidróxido de cálcio e com peróxido de hidrogênio alcalino, a partir de um planejamento fatorial $2^{3}$, visando a otimização desta etapa em termos de rendimentos de açucares fermentescíveis. Para o pré-tratamento com peróxido de hidrogênio, através da ANOVA, verificou-se que apenas os efeitos temperatura, concentração e a interação temperatura/concentração foram significativos com um nível de $10 \%$ e o modelo apresentou um coeficiente de determinação $\mathrm{R}^{2}=98 \%$. Para o tratamento com hidróxido de cálcio todas as variáveis foram significativas com exceção das interações tempo/temperatura e temperatura/concentração. Neste estudo o modelo também apresentou um coeficiente de determinação $\mathrm{R}^{2}=98 \%$.
\end{abstract}

\section{INTRODUÇÃO}

Diante do crescente interesse mundial por fontes de energia limpa e renovável, os materiais lignocelulósicos se destacam como uma alternativa em potencial, uma vez que não competem com a produção de alimentos e são ricos em açúcares que podem servir de matéria-prima na produção de etanol (Doherty et al., 2011).

Em 2011, quase 640 milhões de toneladas de frutas foram colhidas em todo o mundo, (Fao, 2013), gerando uma grande quantidade de resíduos. Com o objetivo de diminuir os impactos ambientais e o elevado índice de desperdício causado pelas indústrias de sucos, tem-se estudado a utilização destes resíduos na produção de bioetanol. A quase totalidade desses resíduos é constituída pelas cascas e sementes das frutas (materiais lignocelulósicos).

A produção de etanol a partir de material lignocelulósico é constituída por quatro etapas: prétratamento, hidrólise, fermentação e destilação. O pré-tratamento tem o objetivo de aumentar a digestibilidade da celulose, reduzindo o seu grau de polimerização e cristalinidade e retirando lignina 
e hemicelulose, que são carboidratos prejudicais para a hidrólise. Existem vários tipos de prétratamento (físico, biológico e químico), dentre eles, aqueles que utilizam álcalis estão recebendo uma maior atenção devido ao seu custo reduzido, menor demanda de energia e eficiência com vários resíduos lignocelulósicos (GHOSH et al. 2012).

Assim, este trabalho teve por objetivo a análise do desempenho do bagaço do abacaxi submetido ao pré-tratamento com hidróxido de cálcio e com peróxido de hidrogênio alcalino. $\mathrm{O}$ estudo foi conduzido tendo como base um planejamento fatorial $2^{3}$ cujos parâmetros eram o tempo, a temperatura e a concentração dos álcalis; e a resposta foi a concentração de açúcar redutor produzido na hidrólise com ácido sulfúrico diluído.

\section{MATERIAIS E MÉTODOS}

\subsection{Preparo do bagaço}

O bagaço de abacaxi foi fornecido pela indústria Dolce Vida, localizada em Anápolis, Goiás. Antes de ser estocada, a biomassa foi seca em estufa a $60{ }^{\circ} \mathrm{C}$ por cinco dias, sendo posteriormente armazenado em recipientes hermeticamente fechados.

\subsection{Planejamento fatorial}

Empregou-se um planejamento fatorial $2^{3} \mathrm{com}$ dois pontos centrais e duas replicatas para cada experimento. As Tabelas 1 e 2 mostram os fatores e os níveis escolhidos para o pré-tratamento com hidróxido de cálcio e com o peróxido de hidrogênio alcalino, respectivamente.

Tabela 1 - Fatores e níveis (reais e codificados) para o pré-tratamento com peróxido de hidrogênio alcalino

\begin{tabular}{|c|c|c|c|}
\hline Ensaio & Tempo $(\mathrm{h})$ & Temperatura $\left({ }^{\circ} \mathrm{C}\right)$ & Concentração $(\%)$ \\
\hline 1 & $6(-1)$ & $20(-1)$ & $1(-1)$ \\
\hline 2 & $24(1)$ & $20(-1)$ & $1(-1)$ \\
\hline 3 & $6(-1)$ & $60(1)$ & $1(-1)$ \\
\hline 4 & $24(1)$ & $60(1)$ & $1(-1)$ \\
\hline 5 & $6(-1)$ & $20(-1)$ & $5(1)$ \\
\hline 6 & $24(1)$ & $20(-1)$ & $5(1)$ \\
\hline 7 & $6(-1)$ & $60(1)$ & $5(1)$ \\
\hline 8 & $24(1)$ & $60(1)$ & $5(1)$ \\
\hline 9 & $15(0)$ & $40(0)$ & $3(0)$ \\
\hline 10 & $15(0)$ & $40(0)$ & $3(0)$ \\
\hline
\end{tabular}


Tabela 2 - Fatores e níveis (reais e codificados) para o pré-tratamento com hidróxido de cálcio

\begin{tabular}{|c|c|c|c|}
\hline Ensaio & Tempo $(\mathrm{h})$ & Temperatura $\left({ }^{\circ} \mathrm{C}\right)$ & Concentração $(\mathrm{g})$ \\
\hline 1 & $20(-1)$ & $40(-1)$ & $1(-1)$ \\
\hline 2 & $40(1)$ & $40(-1)$ & $1(-1)$ \\
\hline 3 & $20(-1)$ & $60(1)$ & $1(-1)$ \\
\hline 4 & $40(1)$ & $60(1)$ & $1(-1)$ \\
\hline 5 & $20(-1)$ & $40(-1)$ & $2,2(1)$ \\
\hline 6 & $40(1)$ & $40(-1)$ & $2,2(1)$ \\
\hline 7 & $20(-1)$ & $60(1)$ & $2,2(1)$ \\
\hline 8 & $40(1)$ & $60(1)$ & $2,2(1)$ \\
\hline 9 & $30(0)$ & $50(0)$ & $1,6(0)$ \\
\hline 10 & $30(0)$ & $50(0)$ & $1,6(0)$ \\
\hline
\end{tabular}

\subsection{Pré-tratamento}

Pré-tratamento com peróxido de hidrogênio alcalino: Amostras de $4 \mathrm{~g}$ de biomassa foram tratadas com $100 \mathrm{~mL}$ de peróxido de hidrogênio $\left(\mathrm{H}_{2} \mathrm{O}_{2}\right)$ e o $\mathrm{pH}$ ajustado para 11,5 pela adição de hidróxido de sódio $(\mathrm{NaOH})$. Foram mantidas em shaker sob agitação de $150 \mathrm{rpm}$. A temperatura, o tempo de reação e a concentração do peróxido de hidrogênio foram estabelecidos pelo planejamento.

Pré-tratamento com hidróxido de cálcio: Amostras de $4 \mathrm{~g}$ de biomassa foram misturadas hidróxido de cálcio $\left(\mathrm{Ca}(\mathrm{OH})_{2}\right)$ em $100 \mathrm{ml}$ de água destilada. Foram mantidas em shaker sob agitação de $150 \mathrm{rpm}$. A temperatura, o tempo de reação e a concentração de hidróxido de cálcio foram estabelecidos pelo planejamento.

\subsection{Hidrólise ácida}

As amostras pré-tratadas foram transferidas para erlenmeyers de $125 \mathrm{~mL}$ e tratadas com $25 \mathrm{~mL}$ de ácido sulfúrico $\left(\mathrm{H}_{2} \mathrm{SO}_{4}\right)$ 2,9\% $\mathrm{m} / \mathrm{v}$. Os erlenmeyers foram fechados com papel alumínio e autoclavados por $30 \mathrm{~min}$ a $121^{\circ} \mathrm{C}$. Após a descompressão da autoclave, os frascos foram retirados e resfriados à temperatura ambiente, sendo a fração sólida separada da fração líquida por filtração em papel de filtro qualitativo.

\subsection{Quantificação dos açucares redutores totais (ART)}

Para a quantificação dos ART utilizou-se o método do ácido dinitro-3,5-salicílico (DNS) descrito por Miller (1959). Para determinar a concentração dos ART das amostras analisadas, foi necessário construir uma curva-padrão de glicose com concentrações variando de 0 a $10 \mathrm{mg} \cdot \mathrm{mL}^{-1}$. Sempre que necessário, foram efetuadas diluições das amostras de modo que a absorbância resultante estivesse contida no intervalo da curva-padrão. 


\section{RESULTADOS E DISCUSSÕES}

Os resultados obtidos nos planejamentos fatoriais $2^{3}$ foram analisados pelo software Statistica 7.0. A análise de regressão múltipla foi aplicada nos dados experimentais e os parâmetros com um nível de significância superior a $10 \%$ foram negligenciados. As variáveis que apresentaram um nível de significância menor do que $10 \%$ em teste t de Student foram as mais pertinentes para o modelo.

\subsection{Pré-tratamento com peróxido de hidrogênio alcalino}

A Tabela 3 apresenta a matriz do planejamento fatorial $2^{3}$ e as respostas de quantidade de ART, produzida após a hidrólise ácida, de cada experimento para o pré-tratamento com peróxido de hidrogênio alcalino.

Tabela 3 - Matriz do planejamento fatorial e respostas de quantidade de açucares redutores totais para o pré-tratamento com peróxido de hidrogênio alcalino

\begin{tabular}{|c|c|c|c|c|}
\hline Ensaio & Tempo $(\mathrm{h})$ & Temperatura $\left({ }^{\circ} \mathrm{C}\right)$ & Concentração $(\%)$ & ART $\left(\mathrm{g} . \mathrm{L}^{-1}\right)$ \\
\hline 1 & $(-1)$ & $(-1)$ & $(-1)$ & 37,09 \\
\hline 2 & $(1)$ & $(-1)$ & $(-1)$ & 38,90 \\
\hline 3 & $(-1)$ & $(1)$ & $(-1)$ & 37,00 \\
\hline 4 & $(1)$ & $(1)$ & $(-1)$ & 39,00 \\
\hline 5 & $(-1)$ & $(-1)$ & $(1)$ & 25,00 \\
\hline 6 & $(1)$ & $(-1)$ & $(1)$ & 22,29 \\
\hline 7 & $(-1)$ & $(1)$ & $(1)$ & 11,13 \\
\hline 8 & $(1)$ & $(1)$ & $(1)$ & 11,35 \\
\hline 9 & $(0)$ & $(0)$ & $(0)$ & 24,50 \\
\hline 10 & $(0)$ & $(0)$ & $(0)$ & 24,70 \\
\hline
\end{tabular}

A partir dos resultados obtidos pelo Statistica 7.0, constatou-se que para o pré-tratamento com peróxido de hidrogênio alcalino as variáveis temperatura, concentração e a interação entre elas foram significativas para o modelo. A Equação 1 representa o modelo linear, onde $\mathrm{T}$ é temperatura e $\mathrm{C}$ é concentração, com $R^{2}=97,7 \%$. As Figura 1, Figura 2 e Figura 3 mostram as superfícies de resposta utilizando o modelo da Equação 1:

$$
[A R T]=27,09-3,1 * T-10,27 * C-3,10 * T * C(1)
$$



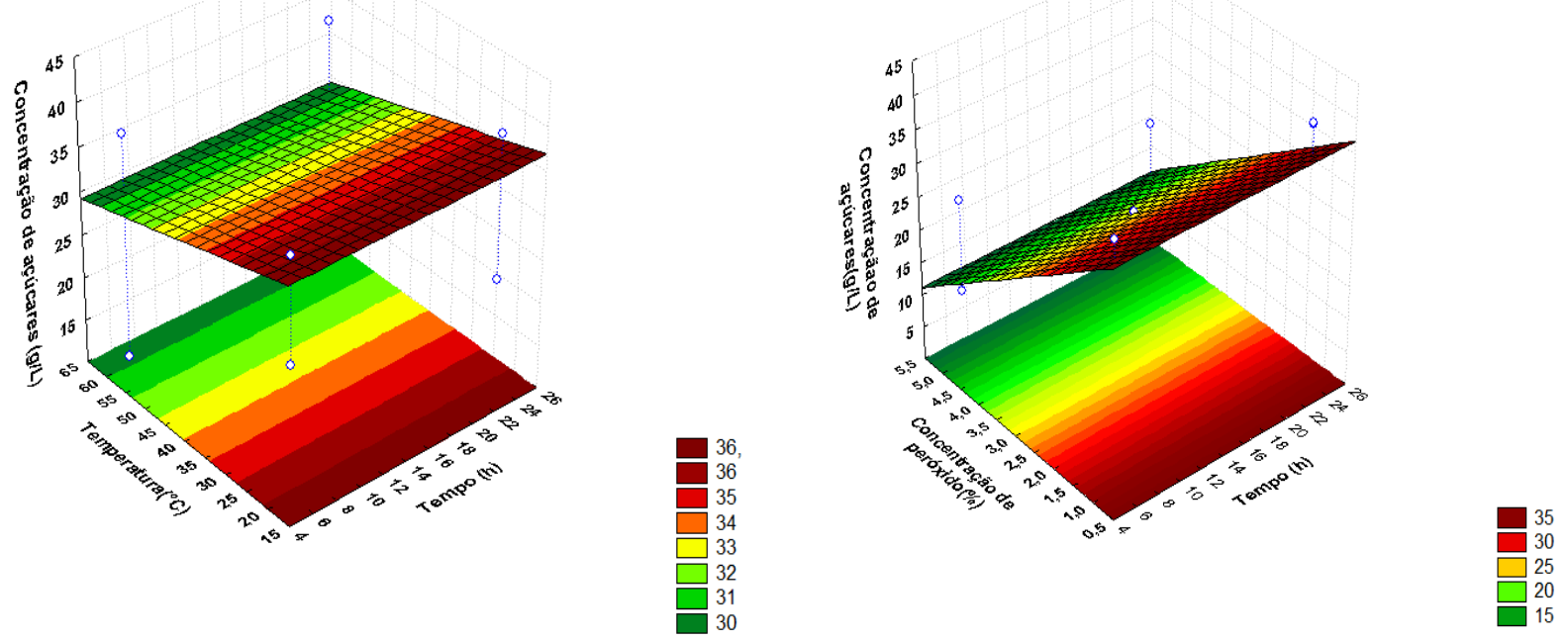

Figura 1 - Superfície de resposta da quantidade de ART como função da temperatura e do tempo.

Figura 2 - Superfície de resposta da quantidade de ART como função da concentração e do tempo.

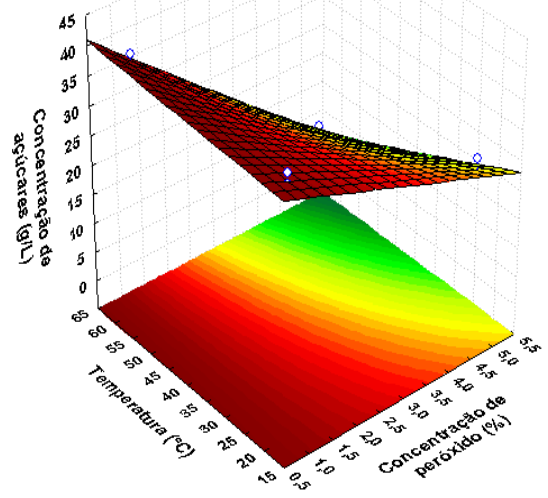

Figura 3 - Superfície de resposta da quantidade de ART como função da concentração e da temperatura.

Ao analisarmos a Figura 1, observa-se que a maior produção de açúcares redutores ocorre nas menores temperaturas. Verifica-se claramente que a variável tempo não tem efeito significativo na resposta, ou seja, as maiores respostas ocorrem em toda a faixa estudada. Sendo assim, o tempo ideal adotado para este pré-tratamento poderá ser o menor. A Figura 2 ilustra um comportamento similar ao da Figura 1 onde a variável concentração de peróxido possui melhores respostas nas menores faixas 
estudadas. A Figura 3 destaca que os pontos de maior concentração de ART são em baixas concentrações e que tanto em temperaturas altas como em baixas o rendimento é praticamente o mesmo. Assim, por um melhor consumo energético, será utilizado as menores temperaturas sem interferir significativamente na obtenção de açúcares fermentescíveis.

Avaliando a Tabela 3, chegaremos às mesmas conclusões ao confrontar os experimentos 3 e 7 e 1 e 5, onde variou-se a concentração e fixou-se as outras variáveis, as melhores respostas são aquelas em que utilizou-se as menores concentrações de peróxido. Ainda observa-se que a variável temperatura, ao comparar-se os experimentos 8 e 6 quando mantida constante e as outras variáveis foram modificadas em seus níveis mais altos (24h e 5\%), a melhor resposta foi para a menor temperatura. Interessante atentar ainda, que ao comparar os experimentos 1 e 3 onde fixou-se o tempo e a concentração em seus níveis mais baixos (6h e 1\%), obteve-se praticamente as mesmas respostas e as maiores em todo o planejamento. Com isto, verifica-se que os melhores resultados estão nas menores faixas das 3 variáveis estudadas (experimento 1) sendo este tratamento adequado por apresentar grande economia de tempo, energia e reagente.

\subsection{Pré-tratamento com hidróxido de cálcio}

A Tabela 4 apresenta a matriz do planejamento fatorial $2^{3}$ e as respostas de quantidade de ART, produzida após a hidrólise ácida, de cada experimento para o pré-tratamento com hidróxido de cálcio.

Tabela 4 - Matriz do planejamento fatorial e respostas de quantidade de açucares redutores totais para o pré-tratamento com hidróxido cálcio

\begin{tabular}{|c|c|c|c|c|}
\hline Ensaio & Tempo $(\mathrm{h})$ & Temperatura $\left({ }^{\circ} \mathrm{C}\right)$ & Concentração $(\%)$ & ART $\left(\mathrm{g} . \mathrm{L}^{-1}\right)$ \\
\hline 1 & $(-1)$ & $(-1)$ & $(-1)$ & 44,93 \\
\hline 2 & $(1)$ & $(-1)$ & $(-1)$ & 42,70 \\
\hline 3 & $(-1)$ & $(1)$ & $(-1)$ & 37,21 \\
\hline 4 & $(1)$ & $(1)$ & $(-1)$ & 37,42 \\
\hline 5 & $(-1)$ & $(-1)$ & $(1)$ & 27,00 \\
\hline 6 & $(1)$ & $(-1)$ & $(1)$ & 14,34 \\
\hline 7 & $(-1)$ & $(1)$ & $(1)$ & 21,18 \\
\hline 8 & $(1)$ & $(1)$ & $(1)$ & 8,50 \\
\hline 9 & $(0)$ & $(0)$ & $(0)$ & 33,40 \\
\hline 10 & $(0)$ & $(0)$ & & 33,10 \\
\hline
\end{tabular}

A partir dos resultados obtidos pelo Statistica 7.0, constatou-se que para o pré-tratamento com hidróxido cálcio as variáveis temperatura, concentração, tempo e a interação tempo/concentração foram as significativas para o modelo. A Equação 2 representa o modelo linear, onde T é temperatura, $\mathrm{C}$ é concentração e $\mathrm{t}$ é tempo, com $\mathrm{R}^{2}=97,8 \%$. As Figura 4, Figura 5 e Figura 6 mostram as superfícies de resposta usando o modelo da Equação 2.

$$
[A R T]=29,97-3,41 * t-3,08 * T-11,4 * C-2,91 * t * C
$$



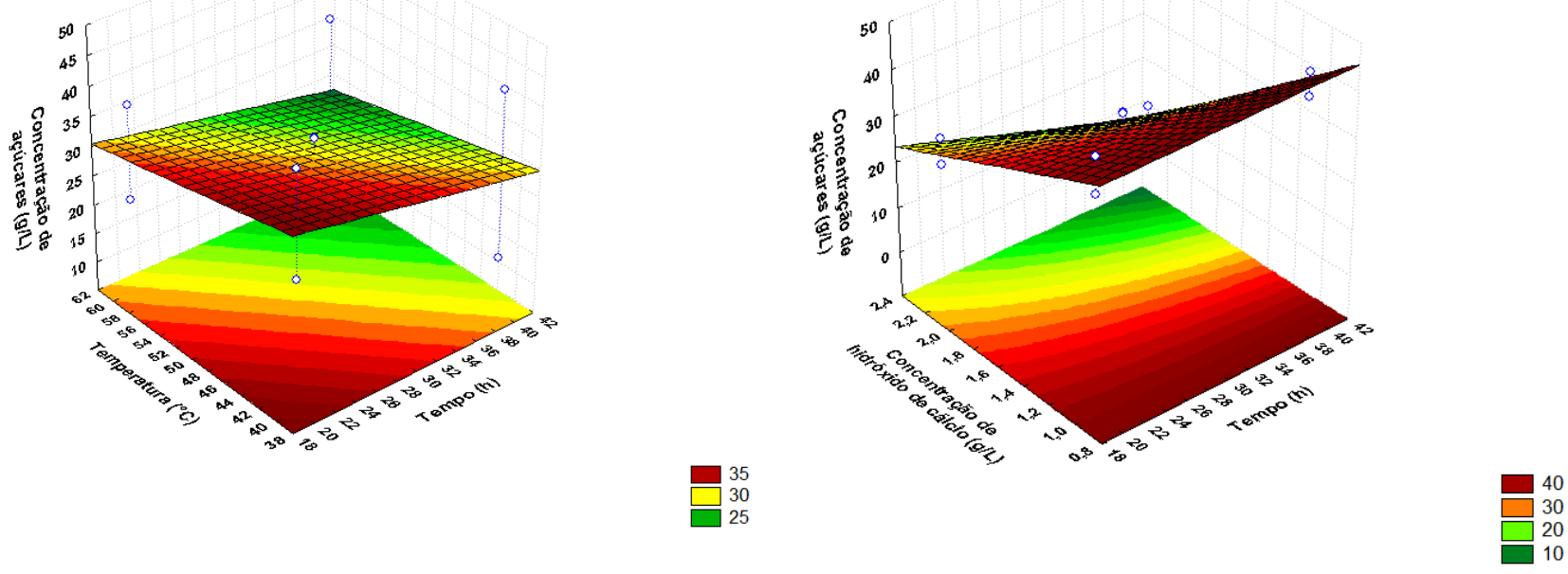

Figura 4 - Superfície de resposta da quantidade de ART como função da temperatura e do tempo.

Figura 5 - Superfície de resposta da quantidade de ART como função da concentração e do tempo.

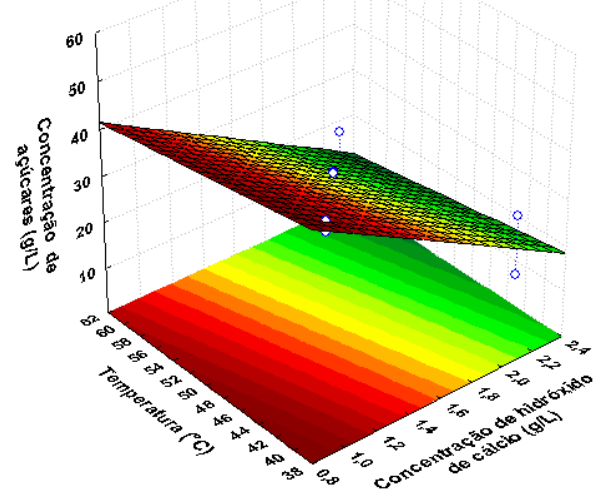

Figura 6 - Superfície de resposta da quantidade de ART como função da concentração e da temperatura.

De acordo com a Figura 4 vemos que as maiores quantidades de ART obtidas são para os menores tempos e também para as menores temperaturas. A Figura 5 mostra que para qualquer faixa de tempo as menores concentrações de $\mathrm{Ca}(\mathrm{OH})_{2}$ obtiveram o ponto de maior liberação de açúcares fermentescíveis. 
A Figura 6 destaca que os pontos de maior quantidade de ART são em baixas concentrações e que tanto em temperaturas altas como em baixas o rendimento é praticamente o mesmo. Assim, podese utilizar menores temperaturas sem interferir significativamente nos resultados, causando economia de energia.

Avaliando a Tabela 4, observa-se que a maior resposta para a concentração de açúcares para o pré-tratamento com hidróxido de cálcio foi obtida no experimento 1 , ou seja, onde utilizou-se os níveis inferiores para todas as variáveis. Prova disto verifica-se ao comparar os experimentos 1 e 3 onde aumentou-se a temperatura de $40{ }^{\circ} \mathrm{C}$ para $60{ }^{\circ} \mathrm{C}$, mantendo as outras variáveis constantes, a resposta diminuiu de 40,93 para 37,2g/L ou seja, quanto menor a temperatura maior a liberação de açúcares. Outra importante observação pode ser feita entre os experimentos 1 e 2, onde ao aumentar o tempo de reação de 20 para 40 horas, mantendo as outras variáveis constantes, a variável resposta também tem seu valor diminuído. Ao se comparar os experimentos 4 e 8 , onde o aumento da concentração de hidróxido, mantendo as outras variáveis constantes, forneceu uma drástica queda no valor da variável resposta provando ser as menores concentrações as que proporcionam maiores concentrações de ART.

\section{CONCLUSÕES}

Os pré-tratamentos com peróxido de hidrogênio alcalino e com hidróxido de cálcio se mostraram efetivos para a produção de açúcares fermentescíveis após a etapa de hidrólise ácida. Os resultados obtidos mostram que os dois pré-tratamentos apresentaram quantidades similares de açucares redutores após a hidrólise ácida. Mesmo sendo efetuados em condições diferentes, ambos foram eficientes em condições mais brandas, de menor temperatura, tempo e concentração.

\section{REFERÊNCIAS}

DOHERTY, W.O.S.; MOUSAVIOUN, P.; FELLOWS, C.M. Value-adding to cellulosic ethanol: Lignin polymers. Industrial Crops and Products, v.33, p.259-276, 2011.

FAO STATISTICAL YEARBOOK 2013 - World Food and Agriculture, pg 138. ISSN 2225-7373

GHOSH, S; CHAUDHARY, G; KUMAR, L. Alkaline pretreatment methods followed by acid hydrolysis of Saccharum spontaneum for bioethanol production. Bioresource Technology, v. 124, p. 111-118, 2012.

MILLER, G. L. 1959, Use of Dinitrosalicylic Acid Reagent for Determination of Reducing Sugar. Analytical Chemistry, 31(3):426-428. 